\title{
Corrupção e teoria econômica ${ }^{\dagger}$
}

Joilson Dias*

Felipe Bento $^{* *}$

RESUMO - O objetivo deste artigo é apresentar uma explicação teórica econômica para a existência da corrupção. Este artigo apresenta uma síntese sobre duas teorias que explicam a corrupção nos países. A primeira tese a ser apresentada do ponto de vista histórico tem por base a teoria do "Estamento Burocrático", de Raymundo Faoro. Esta teoria prevê que o inchaço da máquina pública através de concessões de cargos e criação de órgãos para acomodar o apoio político gera um estamento que utiliza, em segunda instância, estes mesmos cargos públicos em proveito privado. Este proveito privado é feito através de criação de barreiras institucionais que permitem ganhos econômicos a grupos seletos, conforme Bain (1956). Portanto, estas teses explicam a corrupção como sendo uma atividade econômica que precisa ser combatida também do ponto de vista econômico.

Palavras-chave: Corrupção. Teoria econômica. Estamento burocrático. Barreiras à entrada.

\section{INTRODUÇÃO}

A preocupação e a compreensão da corrupção é um fenômeno mundial, não sendo exclusividade brasileira. O programa mundial para políticas anticorrupção teve seu auge com a Convenção Interamericana Contra a Corrupção em Caracas, Venezuela, em 29 de março de 1996. O Brasil, através do Decreto Lei 4.410 de 07/10/2002, adotou a convenção como política de combate à corrupção. Vale ressaltar os dois propósitos desta convenção:

1. promover e fortalecer o desenvolvimento, por cada um dos Estados Partes, dos mecanismos necessários para prevenir, detectar, punir e erradicar a corrupção;

2. promover, facilitar e regular a cooperação entre os Estados Partes a fim de assegurar a eficácia das medidas e ações adotadas para prevenir, detectar, punir e erradicar a corrupção no exercício das funções públicas, bem como os atos de corrupção especificamente vinculados a seu exercício.

\footnotetext{
†Pesquisa financiada através do Projeto Cátedras para o Desenvolvimento do IPEA/CAPES.

* Doutor em Economia pela Universidade da Carolina do Sul. É professor titular do Departamento de Economia da Universidade Estadual de Maringá. Endereço eletrônico: dr.jdias@phdrisk.com.br.

** Graduando em Economia pela Universidade Estadual de Maringá. Endereço eletrônico: fbento1990@gmail. com.
} 
A razão para esta preocupação está nos índices de corrupção medidos para os países pela organização Transparency International ${ }^{1}$ desde 1995. O índice de corrupção da organização Transparency International está entre 1 e 10, sendo 1 utilizado para indicar países altamente corruptos e 10 para países livres da corrupção.

Para ilustrar o caso do Brasil, fizemos um gráfico com os principaís países das Américas. Neste gráfico observamos que o Brasil possuia um índice de corrupção entre 2000 e 2010 abaixo da média 5,0. No período entre 2000 e 2004, o índice brasileiro esteve sempre acima da média dos países do Mercosul. No entanto, este índice caiu nos anos seguintes para 3,7 em 2005, 3,3 em 2006 e 3,5 em 2007-2008 e 3,7 em 2009-2010. Apesar da piora de seu índice, o Brasil no período de 2000-2005 esteve melhor que a média dos Estados do Mercosul, o que significa que nos demais países a corrupção aumentou de forma relativamente superior a do Brasil. Assim, no período mais recente 2006-2010 (excetuando 2009), o índice do Brasil sempre foi inferior a média do Mercosul, claramente indicando que o nível de corrupção no Brasil aumentou vis-à-vis os demais países.

\section{GRÁFICO 1 - ÍNDICE DE CORRUPÇÃO NOS PRINCIPAIS PAÍSES DAS AMÉRICAS 2000-2010}

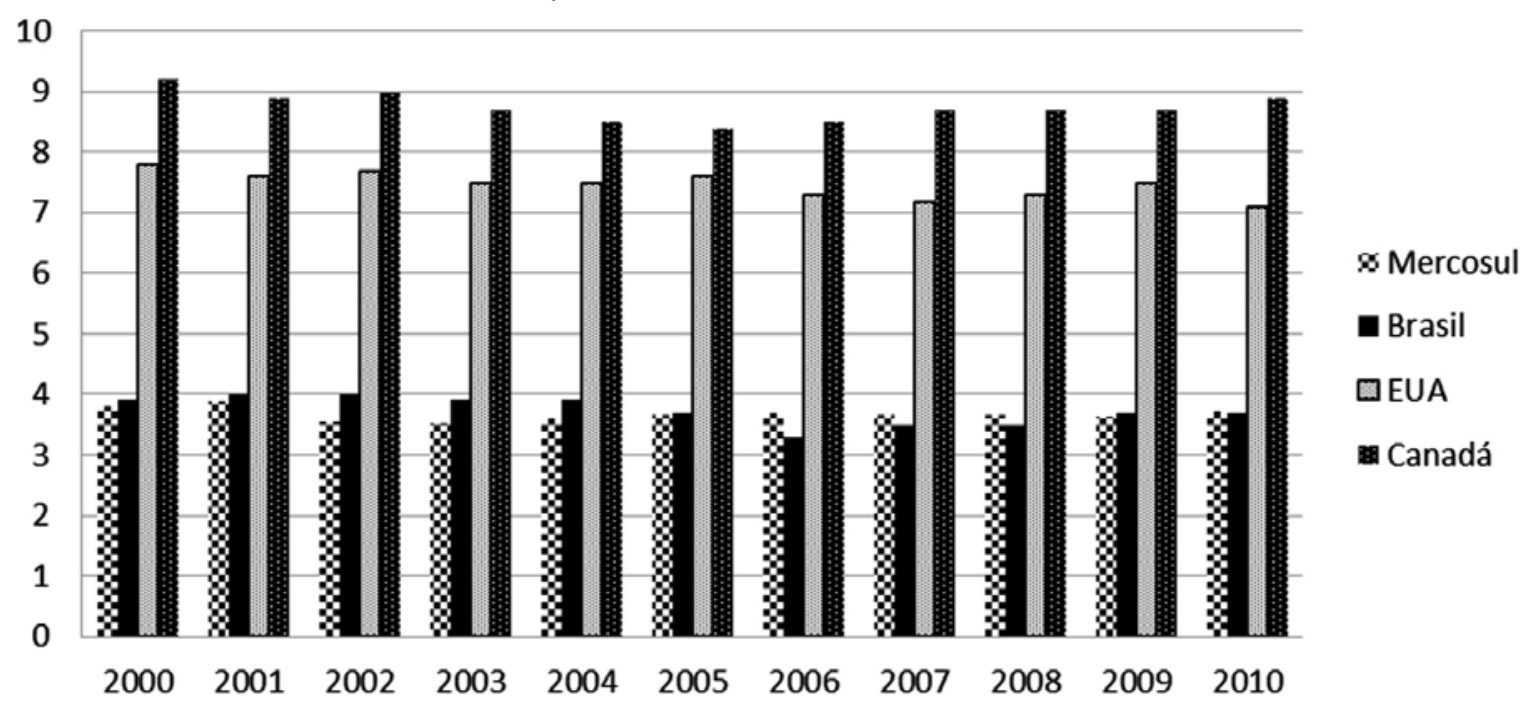

FONTE: Transparency International. Elaboração própria.

Como os índices de corrupção, dos países do Mercosul, de 2010 são inferiores ao de 2000, dez anos atrás, significa claramente que a corrupção vem aumentando entre estes países. Estes índices são inaceitáveis diante dos índices de países como os EUA, que sempre esteve acima de 7,5, exceto nos anos de 2006-2007, em que foi de 7,3 e 7,2, e 2010, que protagonizou o menor índice, 7,1. Mas o exemplo das Américas é o Canadá. Este país mantêm elevados índices de qualidade da administração pública, com relação à corrupção. A queda nos últimos anos

1 Para detalhes da metodologia empregada na pesquisa veja: < http://www.transparency.org.br>. 
ainda produziu um índice em 2010 considerado excelente, de 8,9, mas este país já esteve melhor, em 2000 o seu índice foi 9,2. Os índices indicam que nos últimos dez anos houve um aumento na corrupção nos principais países das Américas.

A pergunta que se faz é: existe uma política no Brasil de combate à corrupção? A resposta é sim. A Corregedoria Geral da União (CGU) é o órgão responsável para coibir, estudar e sugerir leis que visem reduzir a corrupção no Brasil. Portanto, existe um órgão oficial. Este órgão acompanha os estudos e sugestões realizados em nível internacional pela United Nation e demais órgãos internacionais ${ }^{2}$. O enfoque destes órgãos é o de legislação de combate à corrupção. Apesar da importância econômica do impacto da corrupção ser abordado, os estudos do aspecto econômico que corroboram para entender a causa da corrupção ainda são incipientes.

Os estudos da corrupção enquanto aspecto econômico estão voltados para seus efeitos sobre o crescimento e desenvolvimento econômico dos países. Um excelente exemplo destes estudos está em USAID (1998)³. Este número foi dedicado exclusivamente para tratar dos custos econômicos da corrupção em nível internacional.

Ainda sobre os custos da corrupção, destaca-se o trabalho realizado por Speck (2000). O autor realizou uma revisão da literatura com o objetivo de elucidar o papel das pesquisas sobre corrupção. De acordo com o autor, o principal resultado do efeito da corrupção está no impacto que esta tem sobre o funcionamento das instituições. Especificamente, o autor enfatiza a necessidade premente de se adotar uma estratégia que enfatize reformas no sistema político e econômico que eliminem causas estruturais ou institucionais da corrupção, isso é, reformas que melhorem o funcionamento das instituições.

Neste contexto, o principal efeito da corrupção está em debilitar as instituições que governam a economia e estimulam o crescimento e o desenvolvimento de longo prazo. Ou seja, a consequência maior que a corrupção traz para o sistema econômico é a redução dos incentivos à acumulação de capital físico, humano e financeiro. Esta visão está em conformidade com a literatura que enfatiza o papel da qualidade das instituições no crescimento e desenvolvimento econômico dos países, conforme Dias e McDermott (2006), Dias e Tebaldi (2011) e Dias (2011), entre outros autores.

Este artigo se propõe a oferecer uma explicação da corrupção a partir da teoria do "Estamento Burocrático" de Raymundo Faoro (1957) e de barreiras à entrada de Bain (1956). A combinação destas teorias nos parece apresentar o principal incentivo econômico existente para a corrupção. Neste caso, a legislação deve combater este incentivo econômico para sua

2 Veja em: <http://www.unodc.org/unodc/en/treaties/CAC/index.html>.

3 Veja em: <http://www.4uth.gov.ua/usa/english/trade/ijee0500/ijep1198.htm>. 
existência e não somente a corrupção per se.

\section{O FUNDAMENTO MICROECONÔMICO DO ESTAMENTO BUROCRÁTICO}

A tese do estamento burocrático foi apresentada por Raymundo Faoro em seu livro Os donos do poder, de 1957. Segundo sua tese, o estamento burocrático emergiu com a revolução portuguesa de Avis em 1384. Para Faoro (1957, p. 60), o novo Estado português que emerge da revolução é um Estado pensado juridicamente e que se aparelha política e administrativamente: "Esta nova corporação de poder se estrutura numa comunidade: o estamento". O estamento que não tinha objetivo econômico, mas mera ascensão social, muda de característica no tempo. De acordo com Faoro (1957, p. 62): “O fechamento da comunidade (estamento) leva à apropriação de oportunidades econômicas que desembocam, no ponto extremo, nos monopólios de atividades lucrativas e de cargos públicos.”.

Esta forma de governar, segundo o autor, ganhou a denominação de "estamento burocrático”, onde as pessoas em cargos e órgãos governam com o intuíto de obter ganhos econômicos para si próprias através de associações necessárias com as pessoas ligadas ao mercado. Esta forma, na visão do autor, foi predominante no Brasil: “A função pública congrega, reúne e domina a economia. Ela é o instrumento regalista da classe dominante, formando um patriciado administrativo. Por meio dele, amolda-se o complexo metropolitano e se homogeneiza o mundo americano." (FAORO, 1957, p. 201).

O Liberalismo econômico e a liberdade da iniciativa têm, por consequência, no Brasil, uma curta história. A tutela do Estado, desde D. Fernando, com a participação do governo nas atividades econômicas, persistiu no Império e na República. Nossa economia, como afirmou o Sr. Aliomar Baleeiro, viveu sempre do óleo canforado dos "estancos, monopólios, muletas bancárias oficiais, tarifas protecionistas, reajustamentos, equilíbrio estatístico, valorizações artificiais etc.”. [...] O Intervencionismo não é abominado pelos empresários, senão que é desejado, pois a sombra das tarifas alfandegárias, das dificuldades de importação, dos ágios e prêmios, crescem e proliferam indústrias alimentadas dos altos preços e lucros rápidos. Para sustentar estas indústrias sem horizontes e esse comércio especulativo, as emissões - de estímulo ao comércio e a indústria - favorecem o incremento de uma economia especuladora, comercial, ligada a favores do governo. É a classe lucrativa que se reexpande, no consórcio clássico com o estamento burocrático, que se fortifica com o controle da economia. (FAORO, 1957, p. 253).

A pergunta que fazemos é a seguinte: qual é a explicação econômica para que ocorra a dependência dos empresários das pessoas em cargos públicos?

A resposta de Faoro (1957, p. 61) para a nossa pergunta é a seguinte: "Os estamentos 
florescem, de modo natural, nas sociedades em que o mercado não domina toda a economia, a sociedade feudal ou patromonial". Por estamento burocrático entenda-se grupo de pessoas que ocupam função pública. Estas pessoas do estamento burocrático são formadas principalmente por aquelas que controlam a atividade econômica, quer por imposição legal de seus cargos, quer por serem capazes de alterar a distribuição dos ganhos econômicos por meio de legislação ou normas.

Esta colocação significa que o estamento burocrático é capaz de alterar a estrutura de mercado, ou seja, é capaz de determinar barreiras à entrada e/ou incentivos à empresas existentes, de tal forma a alterar a estrutura de concorrência do mercado.

Esta interpretação de barreiras à entrada é condizente com a teoria proposta por Bain (1956). Segundo Bain, a lucratividade e a determinação de preços da empresa estão associados à facilidade ou dificuldade com que outras empresas adentram no mercado. Esta facilidade ou dificuldade são provenientes de barreiras à entrada existentes.

O conceito econômico de barreiras à entrada proposto por Bain (1956) implica na existência de uma condição estrutural que permita às empresas estabelecidas no mercado, ou que pretendem entrar no mercado, praticarem preços superiores aos de mercados sob concorrência. Ou seja, as empresas beneficiadas obtêm ganhos econômicos superiores aos prevalentes em outros mercados, sem atrair novos concorrentes devido às barreiras institucionais. Estas barreiras à entrada são basicamente de duas naturezas, segundo Bain (1956):

1) Barreiras institucionais: os exemplos comuns são os seguintes: as instituições prevalentes no país estabelecem monopólios de concessão, exploração e/ou funcionamento de determinado comércio, indústria ou serviço, criam normas impeditivas a novos entrantes, estabelecem formas de compra de bens e serviços que privilegiam algumas empresas, estabelecem impostos que inviabilizam economicamente a permanência ou entrada de novas empresas etc.

2) Barreiras econômicas: estas barreiras estão associadas a aspectos como, por exemplo, tamanho do capital necessário para o investimento, detenção de conhecimento específico, diferenciação de produtos, preferências de consumidores, economias de escala etc.

A nossa interpretação é que o Estado encontrou uma fórmula ideal de incentivos econômicos que justifica a perpetuação do regime comandado pelo “estamento burocrático", e que 
gera um equilíbrio de mercado a partir de um sistema de controle estatal da economia.

Portanto, a perpetuação somente permanece ao longo da história econômica do Brasil porque cria incentivos econômicos que satisfazem grupos de empresários, ou seja, gera uma economia com a estrutura de mercado controlada pelo estamento burocrático. Isto porque é o estamento que conhece profundamente as normas e as implementam, sendo estas originárias de legislação e, portanto, associadas em certo grau com a esfera política. A garantia e/ou desvirtuamento destas normas são feitos sempre com a complacência do estamento burocrático, pois é ele que fiscaliza a sua implementação em última instância.

Assim, as barreiras institucionais podem emergir a partir das pessoas ligadas ao estamento burocrático ou, ainda, a partir do empresariado interessado em obter previlégios econômicos em determinada atividade econômica ou produto. Em qualquer dos casos, se faz necessária a intermediação do estamento burocrático para que o propósito de se obter vantagens econômicas seja implementado. Desta associação surgem as barreiras através de legislação, normas, de concessão etc., que permitem a empresários, grupos econômicos, obterem ganhos econômicos de monopólios ou quase monopólios. Por exemplo, a concessão de rodovias, que estabelece monopólio completo ao concessionário, é um exemplo típico desta associação. Neste caso, temos o extremo em que o Estado deixa de fazer seu papel crucial de criar infraestrutura e privatiza o mesmo em favor de empresários.

Como podemos ver, a maior implicação dessa associação é a imposição cada vez maior para que o Estado delegue suas funções de segurança, moradia, infraestrutura, educação, por meio de concessões à iniciativa privada, minimizando assim seu papel institucional. A sua receita deixa de ter como objetivo o investimento econômico/social e passa a ter o de contratar pessoas para a sua máquina administrativa. As contratações são feitas para acomodar o apoio político para suas barreiras institucionais. Estes apoios são conseguidos com a criação de órgãos e atividades públicas que não resultam em serviços para a comunidade. A consequência é um aumento do estamento burocrático e o custo de gerenciamento do Estado. Portanto, gera um ciclo contínuo, em que a perda de capacidade de investimento do Estado faz emergir novas associações e formas de exploração econômica de sua atividade que, por sua vez, requerem apoio para serem aprovadas, o que conduz, em última instância, a criação de cargos, órgãos etc.; ou seja, é um ciclo de desenvolvimento histórico.

É importante lembrar que estas barreiras aparecem em formas que vão desde a burocracia necessária à abertura de uma empresa, leis específicas que bloqueiam a concorrência ou criam monopólios e até falseiam editais de licitações públicas. Este efeito de barreiras somente é possível, do ponto de vista estritamente econômico, se houver compensações aos burocratas 
e governantes, que propõem e aprovam leis e editam normas. Portanto, esta tese prevê como consequência a existência de um fator econômico compensatório. Este fator econômico compensatório é conhecido popularmente como corrupção. A prevalência no Estado brasileiro do estado de corrupção é decorrente das barreiras institucionais previstas por Bain, mas que tem origem no estamento burocrático de Faoro.

\section{CONCLUSÃO}

Neste trabalho apontamos que, se as teses associadas de Faoro e Bain estiverem corretas, a consequência maior é que o combate à corrupção proposto pela sociedade organizada estaria com o foco errado. A causa são as leis que criam a burocracia das barreiras à entrada e reduzem o papel do mercado. Estas geram a necessidade de burocratas para controlarem sua aplicação. Esta visão foi bem exposta por Medeiros (2007): “Na medida em que o Estado se criava com base no inchaço de servidores do sistema burocrático, o sistema político ia sendo afiado por um estamento particular balizado nas relações patriarcais entre dominadores e dominados.".

Mais ainda, está havendo um desvio do papel das instituições democráticas na história econômica do Brasil. Estas, em vez de atenderem objetivos econômicos e sociais de redução do custo do Estado, melhoria da concorrência do mercado e maior eficiência dos órgãos legislativos e judiciários, estão fazendo exatamente o contrário aumentando seus custos. Os custos do Estado são aumentados através de salários médios mais elevados, benefícios extras incompátiveis com os vigentes no mercado, em especial aposentadorias, criação e ampliação de órgãos, aumento de impostos e barreiras legais que fomentam a burocracia e, por extensão, ampliam o estamento burocrático. Além disso, esta política estimula instituições públicas a deixarem de fazer seu papel institucional e a transferir este papel para a iniciativa privada ${ }^{4}$, especialmente as atividades que geram ganhos econômicos acima das obtidas no mercado.

Em contraposição a este movimento, temos a sociedade organizada investindo adicionalmente parte dos seus recursos para criar entidades que tentam reduzir estes custos econômicos e sociais do Estado, em especial os representados pela corrupção. Estes investimentos geram, em primeira instância, um aumento do custo social desta mesma sociedade. O que devem fazer então estas entidades?

4 Se pesquisarmos o aumento nos últimos anos de entidades sem fins lucrativos que surgem para substituir o papel social do Estado, vemos o quanto o Estado está abandonando seu papel. O número de entidades sem fins lucrativos atingem 220.000 em 2010, sendo a maioria voltada para interesses de um pequeno grupo, como clube de futebol, associação de bairros, igrejas etc.. Muitas destas instituições são usadas para proveito próprio. Maiores detalhes deste terceiro setor veja em: <http://www.filantropia.org/OqueeTerceiroSetor.htm>. 
As entidades deveriam ter como foco a redução do Estado. Esta redução se faz por meio de redução da carga tributária e imposição ao seu tamanho de gerenciamento, portanto, obriga a eficiência. Os tributos devem ter como destino maior os investimentos em infraestrutura, educação, segurança, moradia etc.; ou seja, no exercício do papel institucional do Estado. Deve ser evitada a criação de órgãos públicos, cargos comissionados e legislações que levam ao aumento de barreiras institucionais, que alteram a estrutura de funcionamento do mercado.

Em resumo, a corrupção somente será reduzida se houver um sistema eficiente de combate aos ganhos econômicos gerados pelo estamento burocrático. O custo econômico a ser imposto aos corruptos e corruptores deve ser muito maior que o potencial de ganho associado com o ato da corrupção. Isto exige legislação e aplicação desta, de forma a impor perdas de bens econômicos a corruptos e corrompidos bem maior que os ganhos obtidos a partir de seus atos. Esta legislação deve implicar em perda total de bens das pessoas envolvidas e penalidades de reclusão, e não somente as penalidades de devolução de recursos obtidos.

Em suma, a sociedade deve atuar de forma a reduzir o tamanho do Estado, aumentar os investimentos públicos, combater as barreiras que inibem o funcionamento da economia de mercado e criar mecanismos econômicos na legislação que inibam a prática da corrupção.

\section{REFERÊNCIAS}

BAIN, J. Barriers to new competition. Cambridge: Harvard University Press, 1956.

DIAS, J. Instituições modernas, crescimento e desenvolvimento econômico no Brasil: a teoria de Raymundo Faoro. In: ENCONTRO CÁTEDRAS PARA O DESENVOLVIMENTO: IPEA/CAPES, 1., 2011, Maringá. Anais... Disponível em: <http://www.ecopar.net.br/artigos. php?l=i>. Acesso em: 15/9/2011.

DIAS, J.; MCDERMOTT, J. Institutions, education, and development: the role of entrepreneurs. Journal of Development Economics, v. 80, n. 2, p. 299-328, 2011.

DIAS, J.; TEBALDI, E. Institutions, human capital, and growth: the long-run institutional mechanism. Texto para Discussão PME-UEM, 2011.

FAORO, R. Os donos do poder: formação do patronato político brasileiro. São Paulo: Globo, 1957.

SPECK, B. W. Mensurando a corrupção: uma revisão de dados provinientes de pesquisas empíricas. Cadernos Adenauer, Rio de Janeiro, n. 10, 2000.

USAID. Corrupção: um obstáculo para o desenvolvimento. Perspectivas Econômicas, v. 3, n. 5, 1998. 